\title{
LITERATURE.
}

The full literature of the subject with excelient eritical reviews may be found in the following publications:

Bendix, F. Die Pentosurie, Stuttgart, 1903.

Neuberg, Carl. Die Physiologie der Pentosen and Glukuronsaüre Ergeb. d. Physiol., 1904, iii, p. 373 .

Klercker, K. O. Studien über die Pentosurie, Nord. med. Arch., 1905, xxxviii, Abt. ii, p. 1 and 55 .

The best clinical article is that on Pentosuria by F. Blumenthal, Modern Clinical Medicine, Diseases of Metabolism, 3906, p. 262.

\section{THE VALUE OF MASSIVE DOSES OF THE SALICYLATES IN THE DIAGNOSIS AND TREATMENT OF ACUTE ARTICULAR RHEUMATISM.}

\author{
By Thomas Wood Clarke, M.D., \\ RESIDENT PHTSICIAN, THE LATKSIDE HOSPITAL, CLEVELAND, OHIO.
}

Fon the last six years, in the treatment of acute articular rheumatism at the Lakeside Hospital, the tendency has been to a progressive increase in the dosage of sodium salicylate employed. Beginning with ten grains every two hours or fifteen grains every four hours, the amount used has been increased to ten grains, fiftcen grains, or even twenty grains hourly in the endeavor to secure the drug effect as promptly as possible. This massive salicylate dosage has seemingly been of such value in the prompt and sure control of symptoms that an analysis of the hospital cases so treated has been undertaken in a critical review of the question. In the review it has seemed only fair, in order, if possible, to learn the exact effect of these large doses, to exclude certain classes of cases. For this reason, all patients who showed an acute complication on admission to the hospital and those in whom, on admission, the temperature was normal, probably due to medication at their homes, have been omitted. Children below twelve years of age have also been excluded on account of the difficulty of classifying these according to dosage. All other cases are included in the analysis.

These exclusions leave seventy-four cases of adults admitted with joints acutely inflamed and temperatures elevated. The discussion of the effects of the large doses of the salicylate, an administration of 240 grains, or more, in the twenty-four hours being considered a large dose, will be divided into two heads, therapeutic and diagnostic.

Therapeutic EFfects. The routine method of treatment has consisted of giving the sodium salicylate every hour, if the patient was awake, in doses varying from 10 to 20 grains, until the toxic symptoms appeared, the attendants being alert to recognize the appearance of deafness and tinnitus, as an index of full drug effect; the salicylate was then stopped, to be resumed when the symptoms 
disappeared, and then given in doses of 10 or 20 grains every two to four hours, stopping again with each recurrence of toxic symptoms. The amount of salicylate required to produce symptoms of its full effect has varied from 75 to 360 grains, the average in the entire series being 200 grains. These massive doses are borne well, as a rule, without nausea, vomiting, or depression, and the coincident relief of pain makes what discomforts there are seem trivial.

Fever. The effect of this sudden saturation with the drug is a very rapid fall of the temperature to the normal. Chart 1 of a patient who became toxic on 165 "grains shows this fall very typically.

Chart 1

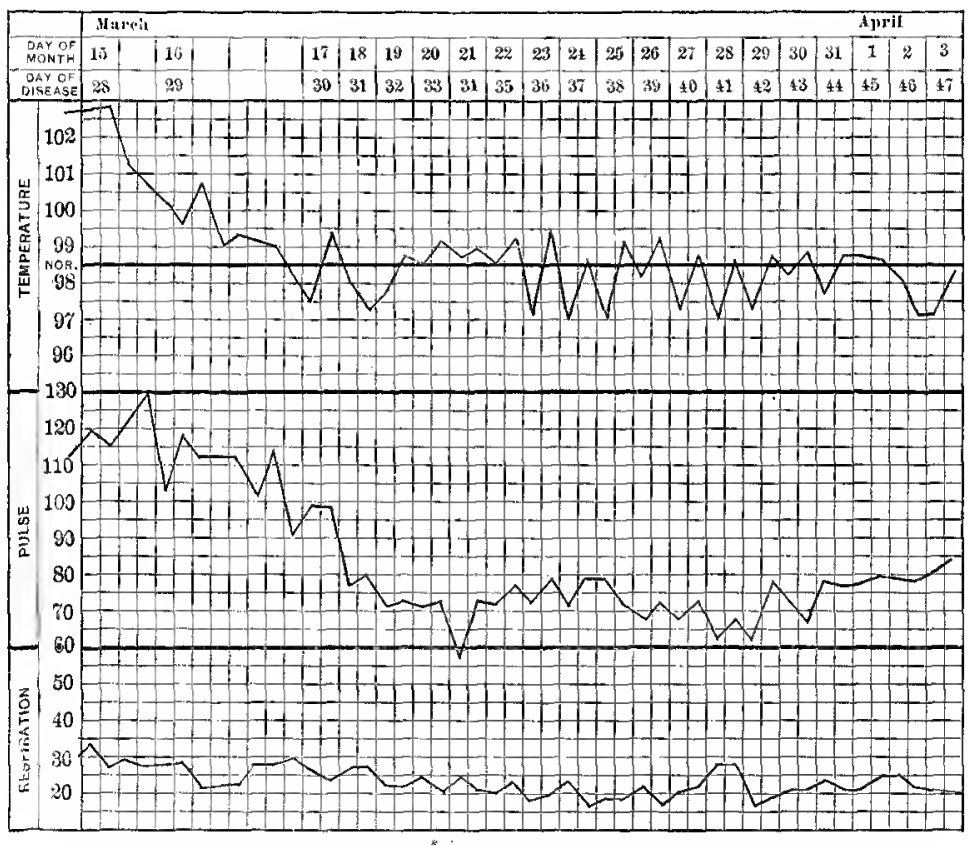

Showing the influence of large doses of salicylates on the temperature, pulse, and respiration of a patient with acute articular rheumatism.

Coming in with a fever of $102.8^{\circ}$ F. at 8 P.M., in twenty-four hours the temperature was $99^{\circ}$, and in thirty-six hours it was subnormal. That this is not exceptional, and is, in fact, what is expected under this treatment, is shown by Chart 2, which is a composite of the temperature of the first three days of the entire series of seventy-four patients. A study of the number of days of fever after the patient's admission shows that the shortest period was one day and the longest eleven days, with an average fever of 3.8 days. The average febrile period of the illness, including the time before treatment was begun, while the patient was still at his home, was thirteen days. 
Pain. The relief from pain is most striking. A patient brought in during the afternoon, in such acute agony that a touch of the bedclothes or a jar of the bed causes a cry of anguish, and who may have required a dose of morphine to allow the nurse to remove his clothing, frequently greets the physician with a smile the following morning at the ward visit, and often moves his joints himself to show his improvement. The pain in some patients is entirely absent on the second day and never returns. Our analysis of the seventyfour cases shows that by the fourth day the average patient is free of discomfort. The longest period of pain has becn nine days.

Swelling. The swelling rapidly subsides, sometimes before the pain, and sometimes persists in a mild degree for a day or two longer. The records upon this point have not been as full as might be desired, but of cases in which the note was made, the swelling disappeared, on the average, on the third day after admission. In

CHART 2

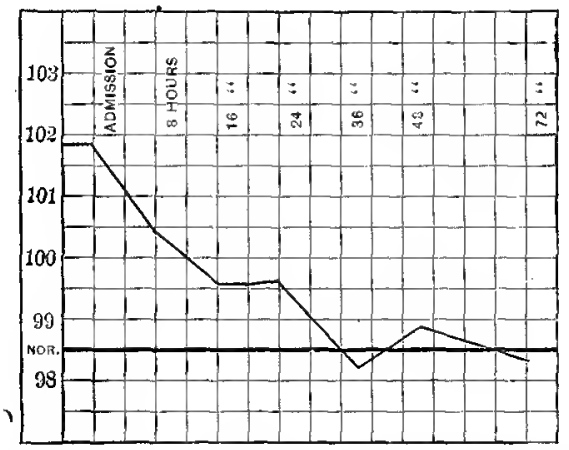

A composite of the temperature of the first three days of seventy-four patients with acute articular rheumatism, showing the intiuenee of large doses of salicylate.

but four of the seventy-four patients has any joint become involved after the treatment was begun.

Heart. Owing to the general belief in the danger to the heart of using the salicylate in large doses this organ has been watched with especial care, and it has been gratifying to see in how few of our cases this fear has been justified. Cardiac complications instead of being increased in frequency by this method of treatment seem to be lessened. The prevalence of acute endocarditis occurring during rheumatism is given by various authors at different rates. W. Gilman 'Thompson ${ }^{\mathbf{1}}$ gives acute endocarditis as occurring in 25 per cent. of the cases; Anders ${ }^{2}$ in from 25 to 30 per cent. Polton ${ }^{3}$ quotes the following authors: Bamberger, 20 per cent.; Wunderlich,

\footnotetext{
1 Amer. Syst. Prac. Med., vol. iv, p. 958.

\& Practice of Medicine, Phila., 1898, 2d ed. p. 206.

3 Jour. Amer. Med. Assoc., 1903, xl, p. 83.
} 
9 per cent.; Bellevue Hospital reports, 33 per cent.; Anders, 40 per cent.; and West, 61.3 per cent. A study of McCrae's recent articles ${ }^{1}$ shows that of 153 patients in whom the heart was clear on admission, 48 at some time developed some sign of cardiac complication, a percentage of 31 , which just agrees with the average of those above mentioned. In our series of 74 patients, 46 had apparently normal hearts on admission to the hospital, and of these, only 6 developed any sign of an endocardial complication. In 4 of these the murmur persisted at discharge, and in 2 it was only temporary and disappeared under observation. This record of 13 per cent. of endocardial complications certainly compares favorably with general experience. There was 1 case of pericarditis in our series of 74 cases. During this period there were several other cases of rheumatic pericarditis in the hospital, but as they were admitted with the complication, they could not be included in this series.

In most of our cases the alkalies in the form of potassium acctate and citrate were given. In eighteen of the cases, however, it was omitted and dependence was put upon the salicylate alone. Though the numbers are too small for conclusions to be drawn, it is of sufficient interest to note in passing that all the six cases of cardiac complications occurred in the patients who received alkalies, and none in the fourteen patients with normal hearts on admission, who were on the salicylate alone.

'The depression of the heart, so often spoken of in connection with salicylate treatment, has not been evident in our cases. The pulse usually drops within three days to from 70 to 80 , as is shown in Chart 1, and remains at that level, strong and regular during convalescence. In one case only in which there was no evident endocarditis has the pulse weakened. In this case it rose to 120 and remained elevated for three days, when it again returned to the normal rate and no further trouble was experienced.

Danger. In the use of such large doses of sodium salicylate there is a certain element of danger. With proper care and attention, however, this is not great. The toxic symptoms must be watched for carefully, and their appearance indicates the immediate stopping of the drug. Again, too, as some persons show no toxic symptoms until they have taken enormous quantities, it would be well to put a limit upon the amount to be given. In the only fatal case in our series the patient took, without any signs of poisoning, 580 grains, at the rate of 20 grains an hour. At this point we discontinued the drug and for two days he did well; then he suddenly became wildly delirious and developed retraction of the head, Kernig's sign, and a high temperature. A lumbar puncture brought out clear fluid under pressure, which showed nothing 
abnormal on examination. The condition continued and progressed until the patient died on the tenth day. The autopsy showed marked cedema of the brain, or serous meningitis, and vegetative endocarditis. We are loth to attribute this man's death to salicylate poisoning, and think it was more likely a case of rheumatic meningitis. The possibility however, must be considered of the drug having caused the symptoms.

The main objection to the use of the massive doses is the difficulty in keeping the patients at rest after the first three days. Feeling comfortable, and, as they express it, cured, most of the unintelligent public ward patients can see no reason for remaining in bed, and clamor to go to their homes to work, and it is often hard or impossible to keep them on their backs for the three weeks after the last symptoms have disappeared, a procedure which has seemed advisable.

Diagnosis. More and more attention is being paid each year to the diagnosis of the various forms of artbritis, particularly to the differentiation of the real cases of rheumatic fever from other infectious forms of arthritis, and especially from the acute stage of arthritis deformans, the latter of particular interest since McCrae's ${ }^{1}$ article on the subject appeared in 1904 . With this point in view the series of cases here reported has been watched, and the impression has steadily gained strength that in using the salicylates in these large doses, they are of value as a diagnostic test. The amount of the drug which a patient will take before becoming toxic is the first point to be considered, and it has constantly been observed that whereas the true rheumatic can tolerate from 150 to 300 grains before symptoms appear, persons suffering from other forms of arthritis become toxic on much smaller doses, the gonococcic cases for example averaging in our series 131 grains. The second point is the relief from symptoms. In true rheumatism the fever, pain, and swelling are gone in from two to three days. In the other forms of arthritis, while the antipyretic effect of the drug may bring the temperature to normal, and while the depressed sensorium may not appreciate the pain so acutely, the swelling does not go down and, as soon as the toxic effects of the salicylate wear off, the pain returns with all its old vigor. The result of this has been that, on this service, any patient having fever and pain at the end of forty-eight hours is considered as a doubtful case of rheumatism and most careful search is instituted for the underlying cause of the arthritis. A resume of the cases of gonorrheal arthritis to which the massive doses were given, during recent years, shows by contrast to the above an average run of fever of twentyone days after admission, of pain of twenty-six days, and of swelling of thirty-one days. These numbers should really be larger

I Jour. Amer, Med Assoc, 1904, xlii, pp. 8, 94, and 161. 
than this shows, as in many cases the date used is that on which the patient was transferred to the surgeons before improvement had begun. An attempt to review the cases of typhoid and other infectious arthritis, of arthritis deformans, tuberculous joints, and gout showed so few cases treated with massive doses of salicylates that they could not be used in comparison.

I was especially impressed with this point in analyzing the histories for this report by finding one ease which differed most materially from the others. 'The history, taken in 1901, was of a man admitted with acute polyarthritis, who, although he received 15 grains of the sodium salicylate every hour did not respond to treatment in the uniform manner of the other cases of the series. It was a typical case of rheumatism and was so diagnosed at the time. On re-reading the history to find an explanation for the failure of response to the drug, the patient's name being noticed for the first time; it was recognized as that of a patient at that time, four years later, in the ward with the typical chronic spondylitis and dactylitis of arthritis deformans.

Conclusions. 1. Sodium salicylate can and should be given in much larger doses than are generally used.

2. Given in massive doses it reduces the fever, relieves the pain and swelling, and shortens the course of the disease.

3. It is not injurious to the heart, and appears by quickly cutting off the disease to offer some protection to that organ.

4. The patient's tolerance to the drug and the rapid cessation of symptoms form valuable therapentic tests for the diagnosis of acute articular rheumatism.

For permission to use the cases from the medical service, I wish to thank Drs. Hunter Powell, John H. Lowman, Henry Upson, and Edward F. Cushing, visiting physicians to the Hospital and especially Dr. Cushing, for many suggestions and ideas, tere used, and for oversight and criticism of the work during preparation.

Since writing this article my attention has been called to the Harveian Lecture of Dr. Lees, ${ }^{1}$ who has made a careful study of the use of massive doses of salicylates in rheumatism.

1 The Treatment of Acute Visceral Inflammations, London, 1904. 